\title{
Central government versus local control
}

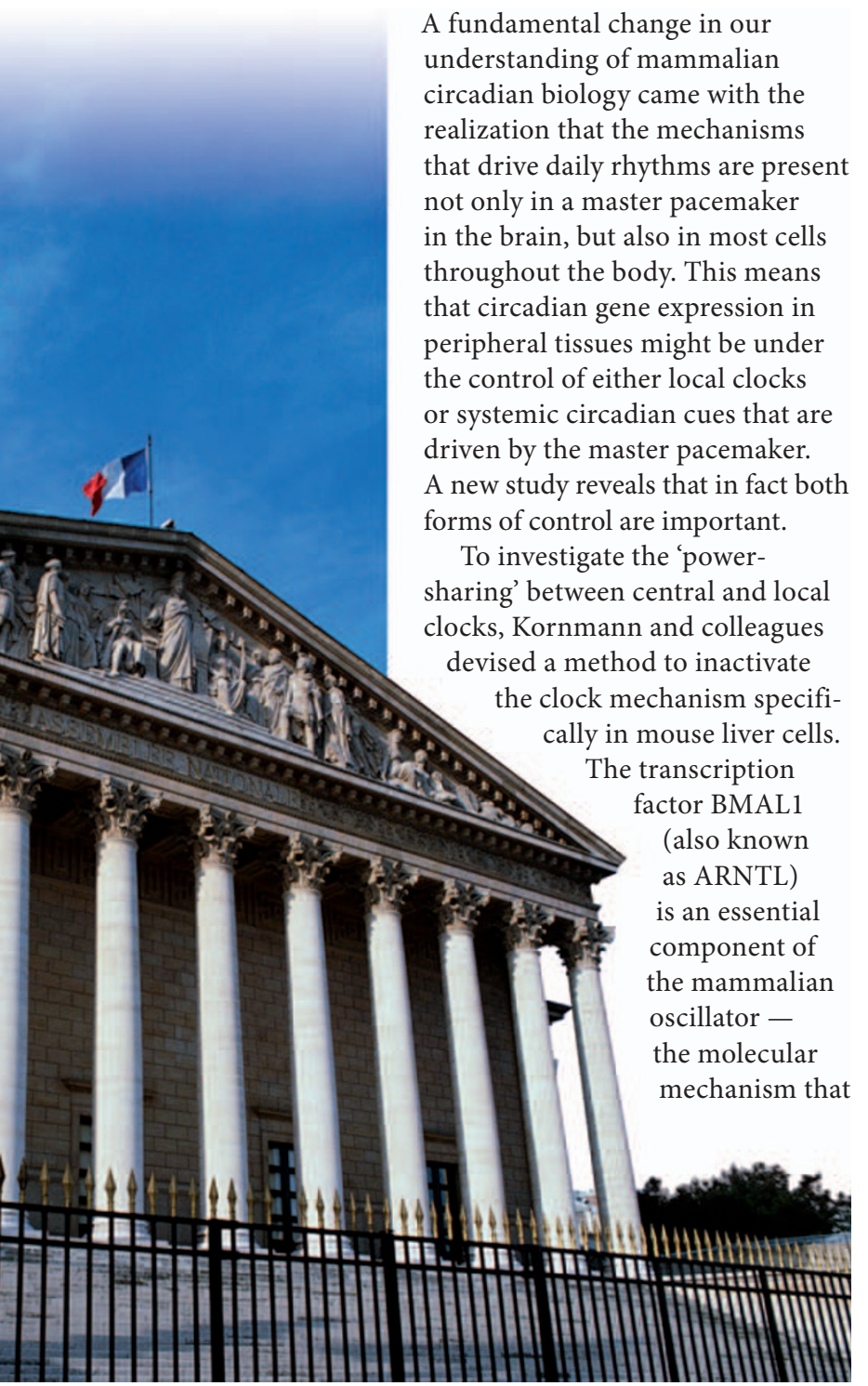

drives circadian rhythmicity - and is negatively controlled by another protein, REV-ERB $\alpha$ (also known as NR1D1). The authors generated transgenic mice in which Rev-erba is expressed in the liver only, under the control of tetracycline-responsive elements. So, the expression of BMAL1 could be turned on or off through Rev-erba expression in a tightly controlled way using dietary supplements.

Kornmann and colleagues used microarray hybridization to assess alterations in genome-wide expression patterns when BMALI expression is repressed in the liver. For most transcripts that usually show a circadian expression pattern, normal cycling was altered when BMAL1 levels were low, indicating their dependence on the functioning of the local oscillator in the liver. However, a smaller subset of transcripts that fall into this class were unaffected by the downregulation of BMAL1 expression. These are good candidates for genes whose circadian regulation is controlled by systemic cues.

Intriguingly, one of the genes that fell into this latter category was period homologue 2 (Per2), another key component of the oscillator mechanism - a surprising finding as Per 2 is transcriptionally activated by BMAL1. The authors investigated the relative contributions of these two modes of Per 2 regulation by monitoring the expression of this gene in cultured liver explants - where systemic signals cannot operate. In liver explants from mice in which BMAL1 is downregulated, circadian Per2 expression was abolished. So, it seems that Per 2 expression can be driven by local clocks in the liver as well as by systemic cues.

This study provides several new insights into mammalian circadian biology. First, local oscillators and systemic cues both seem to regulate circadian patterns of gene expression in peripheral tissues. Second, the fact that an oscillator component, PER2, can be regulated independently of the local clock mechanisms makes it a potential point for synchronization of local oscillators by the central pacemaker. Kornmann and colleagues already have evidence that PER2 expression is temperature dependent. Exploring the roles of body temperature and other potential systemic cues that regulate circadian expression in peripheral tissues will be an important next step.

Louisa Flintoft

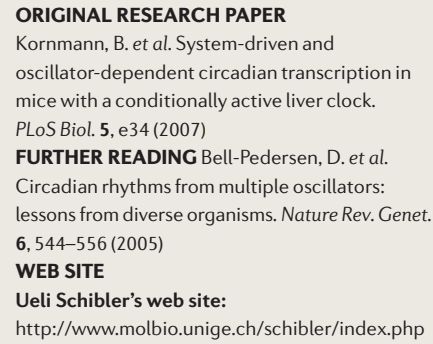

\section{RESEARCH HIGHLIGHTS ADVISORS}

MICHAEL AKAM

University of Cambridge, UK SEAN B. CARROLL

University of Wisconsin, USA NANCY J. COX

University of Chicago, USA

SUSAN FORSBURG University of

Southern California, USA
RALPH J. GREENSPAN

The Neurosciences Institute, California, USA YOSHIHIDE HAYASHIZAKI Riken Genomic Sciences Center, Japan MARK JOBLING

University of Leicester, UK
PETER KOOPMAN

University of Queensland, Australi LEONID KRUGLYAK Fred Hutchinson Cancer Research Center, USA BARBARA MEYER University of California, Berkeley, USA
JOHN QUAKENBUSH

Dana-Farber Cancer Institute and Harvard School of Public Health, Boston, USA JANET ROSSANT

Mount Sinai Hospital, Toronto, Canad MARC VIDAL Dana-Farber Cancer Institute, Boston, USA
VIRGINIA WALBOT

Stanford University, USA DETLEF WEIGEL Max Planck Institute for Developmental Biology, Germany PHIL ZAMORE

University of Massachusetts, USA LEONARD I. ZON

Children's Hospital, Boston, USA 